\title{
PRÁTICAS COLABORATIVAS NA DISCIPLINA DE ESTÁGIO SUPERVISIONADO: ALTERNATIVAS AOS 'MISTÉRIOS' DO LETRAMENTO ACADÊMICO
}

\author{
Marília Curado VALSECHI \\ Universidade Federal de São Carlos
}

\begin{abstract}
RESUMO: Este trabalho apresenta resultados de uma pesquisa de doutorado sobre o estágio supervisionado na formação inicial do professor de língua portuguesa de uma universidade pública paulista. Ancorada na abordagem sociocultural dos Estudos de Letramento e na teoria socioenunciativa do Círculo de Bakhtin, a pesquisa teve por objetivo analisar os modos de inserção dos estagiários nas práticas situadas relativas ao estágio supervisionado. O paradigma teórico permite conceber o estágio enquanto prática acadêmica-profissional, cuja interface entre ambas as esferas - acadêmica e profissional - potencializa a configuração do estágio como entrelugar socioprofissional (REICHMANN, 2012; 2015). Partindo da metodologia qualitativo-interpretativista, de cunho etnográfico, uma variedade de dados foi utilizada, como o planejamento da disciplina, diários de campo, aulas áudio-gravadas, textos produzidos pelos estagiários (ex. relatórios de estágio), documentos da universidade e entrevistas semiestruturadas com professores formados (outrora estagiários). $\mathrm{O}$ estudo aponta que há práticas formativas de estágio mais colaborativas e compreensíveis quanto aos objetivos e modos de realização, as quais favorecem a negociação entre letramentos acadêmico e profissional, além do fortalecimento da identidade profissional docente, e outras que, assim como as práticas acadêmicas dominantes, constituem-se práticas institucionais de mistério (LILLIS, 2001). Os resultados apresentados neste artigo mostram que a construção do estágio como entrelugar socioprofissional depende da negociação entre as práticas de letramento acadêmico e profissionais e também do engajamento do estagiário na participação e valoração de suas práticas. Por isso, é importante a adoção de abordagem de ensino culturalmente sensível aos sujeitos na formação universitária.
\end{abstract}

PALAVRAS-CHAVE: estágio supervisionado; entrelugar socioprofissional; práticas institucionais de mistério.

ABSTRACT: The paper brings results from a research of a two-year guided internship program for Portuguese language teacher training in a public state university in the state of São Paulo. This research is based on the New Literacy Studies socio-cultural approach and on the enunciative theory of Bakhtin's Circle. The investigation aims to analyze the trainee's learning of situated practices during the internship. The theoretical paradigm allows us to conceive the internship program as a professional and academic practice, whose interface between both spheres - academic and professional - increases the potential of the internship becoming a socio-professional in-betweenness (REICHMANN, 2012; 2015). From a methodological perspective, the research is qualitative-interpretative and ethnographic, with a large corpus, like the lesson plans, field diary, class audio recordings, trainees' academic texts (ex. internship report), university documents and semi-structured interviews with students after graduate. The study reveals that there are internship training practices more collaborative and understandable in terms of the goals and modes for development, that favor the negotiation between academic and professional literacies, besides the strengthening of the students' professional teacher identity, and there are others that constitute institutional practices of mystery (LILLIS, 2001), as well as the dominant academic practices. The results presented in this paper show that the construction of the internship as a socio-professional inbetweenness depends on the negotiation between academic and professional literacy practices and also the trainee's engagement in the participation and valuation of its 
practices. Therefore, it is important to adopt a culturally sensitive approach to teaching in university education.

KEYWORDS: internship program for language teachers; socio-professional in-betweenness; institutional practices of mystery.

\section{Introdução}

Tradicionalmente investigado na área da Educação, o estágio supervisionado vem tornando-se foco de pesquisas inseridas no campo da Linguística Aplicada (LA), das quais este trabalho ${ }^{1}$ constitui-se de um exemplo. Além da centralidade na linguagem, compreendida de modo processual (MOITA LOPES, 1996), a transdisciplinaridade e o compromisso éticopolítico, ligado à relevância social da pesquisa, são características da LA presentes no estudo em foco. Em primeiro lugar, a pesquisa assume uma agenda ética ao investigar um componente historicamente apendiculado na formação do professor com vistas a legitimar a voz dos sujeitos que atuam neste, cuja agência é historicamente apagada, e também a fornecer subsídios para se repensar as práticas de estágio supervisionado na formação de professores no contexto universitário. Quanto à transdisciplinaridade, esta se faz presente à medida que os saberes teórico-metodológicos de diversas disciplinas, tais como Filosofia da Linguagem, Estudos de Letramento, Linguística Textual, Educação, articulam-se e interagem entre si na compreensão do objeto de estudo.

A escolha pelo objeto de estudo está ligada à minha atuação profissional enquanto professora universitária responsável pelas disciplinas de estágio supervisionado em Língua Portuguesa do curso de Letras noturno de uma instituição de ensino superior pública paulista. No meu trabalho como professora universitária, ainda que como professora substituta, tive contato com uma série de desafios na realização do estágio supervisionado, das mais diversas ordens: dificuldade do licenciando do curso noturno em conciliar horário para a consecução dos estágios com o trabalho, muitas vezes em período integral; excesso de cobranças acadêmicas, tendo em vista outras disciplinas; além da dificuldade em lidar com a relação professor-aluno e a sensação de impotência no convívio escolar, como já apontado por autores como Pimenta e Lima (2011). De outro lado, como professora universitária, também encontrava dificuldades, como a impossibilidade para acompanhar os estagiários nas escolas devido ao elevado número de estagiários e escolas envolvidos.

Tendo em vista esses desafios, de um lado, e concebendo o estágio como relevante para a formação docente - dada a aproximação que pode promover entre universidade e escola -, de outro, interessei-me em investigar esse objeto complexo, a fim de compreender como os estagiários participavam das práticas de letramento demandadas pela disciplina de estágio, que valores atribuíam aos eventos de letramento em que se inseriam e de que maneira a estruturação do estágio pela instituição de ensino superior contribuía para a construção da apreciação dos estagiários sobre o estágio. Tais objetivos me levaram a identificar dois tipos de práticas de letramento no referido contexto formativo universitário, em especial na disciplina de estágio ministrada por mim, e o objetivo deste artigo é apresentar um exemplo de cada tipo de prática.

\footnotetext{
${ }^{1}$ Este trabalho é oriundo de uma pesquisa de doutorado concluída, realizada sob orientação da Profa. Dra. Angela Kleiman e defendida no Programa de Pós-Graduação em Linguística Aplicada do Instituto de Estudos da Linguagem (IEL/UNICAMP). Inserida no Grupo Letramento do Professor, a pesquisa foi financiada pela CAPES nos anos de 2012 a 2016.
} 
Da série de dados gerados ao longo da minha atuação como professora - planejamento das duas disciplinas anuais de estágio ministradas por mim para a turma que constitui os sujeitos de pesquisa, meus diários de campo, aulas áudio-gravadas, textos dos estagiários e entrevistas com professores recém-formados (ex estagiários) -, neste artigo, analiso um dado de interação em sala de aula, uma nota de campo e um excerto de entrevista. O paradigma epistemológico assenta-se, sobretudo, na perspectiva sociocultural dos Estudos de Letramento e na abordagem dialógica da linguagem, apresentadas na próxima seção.

De acordo com os propósitos deste artigo, organizo-o da seguinte forma: na próxima seção, apresento o principal arcabouço teórico do estudo; em seguida, trago a análise do excerto de uma entrevista com um dos sujeitos de pesquisa sobre a elaboração dos planos de aula das regências; na seção subsequente, analiso um dado de interação em sala de aula cujo tema é a produção de trajetórias de leituras dos alunos estagiários no blog da turma. Finalizo o texto com alguns apontamentos que encerram o artigo.

\section{Perspectiva epistemológica}

Para os integrantes do Círculo de Bakhtin, a linguagem é, por natureza, dialógica, no sentido de que todo enunciado é sempre resposta a enunciados anteriores e, ao mesmo tempo, suscita outras respostas. Em vários momentos da obra Estética da criação verbal, Bakhtin ([1979]/2003) reitera que todo enunciado é um elo da cadeia verbal da comunicação humana. Esta perspectiva dialógica constitui-se de uma abordagem muito profícua para os estudos da linguagem, visto que contempla os fatores socio-históricos (tanto micro quanto macrocontextuais) como elementos constitutivos da linguagem.

Decorre desta concepção uma série de conceitos pertinentes para este trabalho, dentre eles, o de esfera da comunicação humana. Todo enunciado é produzido - oralmente ou por escrito - no interior de um campo específico da comunicação humana, onde outros discursos circulam. Não se trata de um lugar ou espaço físico, mas ideológico. Além das formas de dizer, a esfera define também os possíveis participantes da enunciação, os tipos de relações sociais entre eles (interpessoais e institucionais) e os conteúdos temáticos possíveis (cf. ROJO, 2013). Na esfera acadêmica, por exemplo, admite-se como participante de uma enunciação um professor acadêmico, um pesquisador ou aluno; mas não se admite um líder religioso no exercício de sua atividade. Pode até ser que um indivíduo que assuma a função de uma liderança religiosa em alguns momentos da sua vida também pertença a uma comunidade acadêmica, como aluno de graduação, por exemplo; no entanto, em uma enunciação que ocorre na esfera acadêmica, é do lugar social de aluno de graduação que este sujeito vai participar, não como líder religioso. De maneira análoga, ao presidir uma cerimônia religiosa, a relação institucional que se estabelece entre os participantes é de um líder religioso, com seu poder de autoridade, com os fiéis seguidores, não cabendo o papel de aluno de graduação.

Outro conceito decorrente da teoria socioenunciativa do Círculo bakhtiniano que interessa à pesquisa diz respeito a vozes sociais. Surgido na teoria do romance, este conceito é estendido pelo próprio Bakhtin a toda a forma de enunciação, pois, sendo a palavra "uma arena em miniatura onde se entrecruzam e lutam os valores sociais de orientação contraditória" (VOLOCHINOV, [1929]/2004, p.66), em todo enunciado emergem vozes sociais, que são as entonações, visões de mundo construídas sócio-historicamente. Importante 
ressaltar que a mobilização das vozes sociais independe da consciência dos sujeitos ou de um contato sistemático com elas. Em todo enunciado, ressoam vozes sociais, que se chocam e se entrecruzam e é com base nesse embate de vozes que os sujeitos constroem sua apreciação valorativa.

Segundo Volochinov (2004, p.132), toda palavra tem acento apreciativo. "Sem acento apreciativo, não há palavra". Assim, em toda palavra há um acento de valor, correspondente aos sentidos imbricados nos enunciados atribuídos pelos próprios interlocutores em relação a si mesmos e ao objeto de discurso.

Além de uma importante base teórica sobre a linguagem, a pesquisa também suscita uma abordagem teórica que se debruce sobre as práticas que envolvem a escrita. Condizente com a teoria socioenunciativa bakhtiniana, a teoria sociocultural dos Estudos de Letramento (STREET, 1984; HEATH, 1982; KLEIMAN, 1995) complementa o principal arcabouço teórico deste trabalho.

$\mathrm{Na}$ abordagem sociocultural dos Estudos de Letramento, a escrita é uma prática social, situada e permeada por relações de poder. Assim, alinhando-me ao Grupo de Pesquisa Letramento do Professor, entendo letramento como "um conjunto de práticas sociais, cujos modos específicos de funcionamento têm implicações importantes para as formas pelas quais os sujeitos envolvidos nessas práticas constroem relações de identidade e de poder" (KLEIMAN, 1995, p. 11). Com base nessa compreensão, o conceito letramento do professor contempla muito mais do que apenas o saber relativo ao conteúdo da disciplina, envolvendo os conhecimentos didático-pedagógicos e socioculturais sobre a comunidade alvo, além os conhecimentos subjetivos oriundos da experiência profissional, dos quais resultam as estratégias e procedimentos de ensino (KLEIMAN; SILVA, 2008). De modo geral, envolve o conjunto de saberes, os aspectos sociais e culturais e a dimensão identitária envolvidos na participação das práticas de leitura e escrita necessárias e pertinentes ao trabalho do professor.

Entendo prática social conforme Scribner e Cole (1981, p.236), ou seja, "formas socialmente desenvolvidas e padronizadas de usar a tecnologia e conhecimento para realizar tarefas" sendo estas "direcionadas por objetivos socialmente reconhecidos e [que] demandam uso de conhecimento e tecnologia compartilhados 2 ". Tendo por base essa noção de prática social, o conceito de prática de letramento está ligado às "formas culturais em geral de usar a língua escrita que as pessoas adotam nas suas vidas" ${ }^{3}$ " (BARTON; HAMILTON, 2000, p.7). Trata-se, portanto, de uma concepção cultural ampla dos modos específicos de pensar a leitura e a escrita, incluindo a concepção sobre seus modos de realização em contextos culturais, como destaca Street (2012). De acordo com o autor, o conceito de prática social permite entender os modelos culturais que as pessoas carregam e atualizam na participação de eventos. Práticas de letramento não são observáveis, nem descritíveis; elas são abstraídas dos eventos de letramento, estes sim, observáveis e passíveis de descrição.

\footnotetext{
2 Tradução minha do original: "socially developed and patterned ways of using technology and knowledge to accomplish tasks. (...) [that] are directed to socially recognized goals and make use of a shared technology and knowledge system".

${ }^{3}$ Tradução minha do original: "the general cultural ways of utilising language which people draw upon in their lives".
} 
Heath (1982), no estudo sobre modos de participação de crianças e adultos de comunidades distintas no evento de contação de histórias para dormir, atribui um papel importante ao conceito evento de letramento, pois a sua descrição permite chegar aos valores e regras que cada comunidade se apropria para interagir socialmente. E assim define a autora os eventos de letramento: "ocasiões nas quais a língua escrita está integrada à natureza das interações dos participantes e a seus processos interpretativos e estratégias ${ }^{4}$ " (HEATH, 1982, p. 50). Nesse sentido, o código escrito não precisa estar presente para que se configure como um evento de letramento, pois é a escrita entendida como sistema simbólico, ideológico, que se constitui como elemento central na organização da interação. Por exemplo, uma conversa cotidiana entre duas pessoas que comentam uma notícia de jornal divulgada na televisão constitui-se como um evento de letramento, pois a interação se organiza ao redor de um texto que se origina pela escrita (fatos são computados, registrados, organiza-se o texto escrito para ser oralizado na transmissão televisiva). Percebe-se que, nesta concepção, escritura e oralidade não se contrapõe, mas se complementam.

Articulando ambas as teorias - a socioenunciativa do Círculo e a sociocultural dos Estudos de Letramento -, pode-se afirmar que, em cada esfera discursiva, os sujeitos se inserem em uma variedade de eventos de letramento, mobilizam diferentes práticas de letramento. Nessa perspectiva, o estágio supervisionado pode ser concebido como um entrelugar socioprofissional, tal como define Reichmann (2012, 2015), um lugar de trânsito entre a esfera acadêmica e a profissional docente, pois ao mesmo tempo em que o estagiário está inserido em seu futuro local de trabalho, participando de situações de trabalho, ou eventos de letramento profissional, sua ida à escola é condicionada por uma demanda formativa da universidade, ele é orientado por um professor acadêmico, que lhe solicita a elaboração de textos que vão além dos exigidos pela esfera profissional propriamente, e o estagiário também participa de aulas e discussões na universidade; portanto, também se configura como evento de letramento acadêmico. E esse movimento de ida à escola e à universidade tem potencial para fortalecer a identidade profissional docente. Elaborei a figura abaixo (cf. VALSECHI, 2016) para ilustrar a noção de entrelugar socioprofissional:

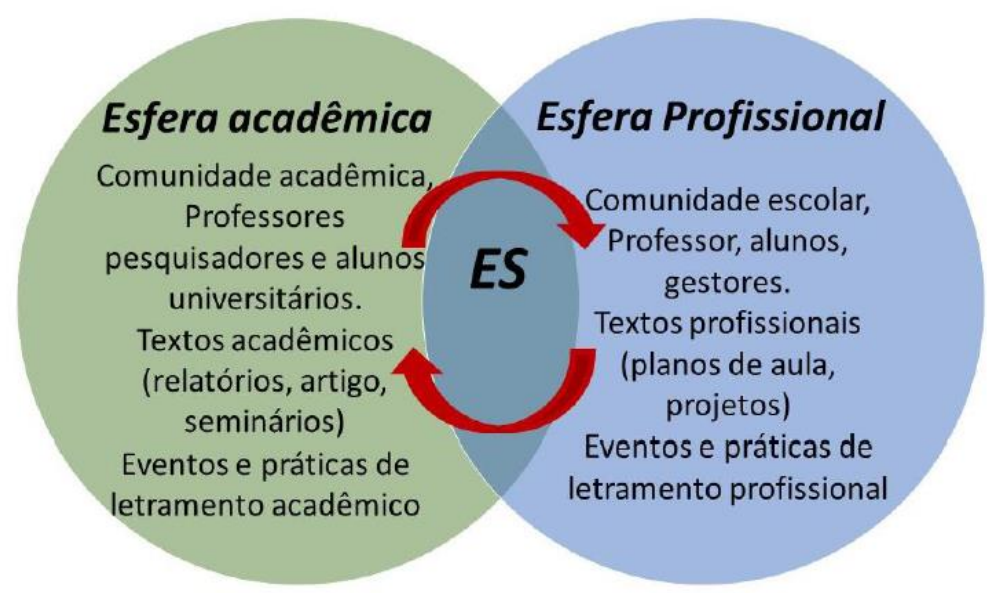

Figura 1: esquema do estágio como entrelugar socioprofissional Fonte: Valsechi (2016)

\footnotetext{
4 Tradução minha do original: “occasions in which written language is integral to the nature of participants' interactions and their interpretive processes and strategies".
} 
As setas vermelhas indicam o movimento de trânsito da esfera acadêmica para a esfera profissional e desta para a acadêmica. Ressalto que a designação "esfera profissional" não se confunde com "esfera escolar", uma vez que, embora se interceptem, a esfera escolar inclui sujeitos, relações interpessoais e institucionais e discursos que não condizem com a esfera profissional e vice-versa, conforme já apontou De Grande (2015). Reuniões de corpo docente, por exemplo, nas quais não se prevê a participação de alunos está mais relacionada à esfera profissional. Na esfera acadêmica, o sujeito estagiário faz parte da comunidade acadêmica, interage com seus pares, na posição de aluno, e com professores universitários, inclusive o responsável pelo estágio, que propicia eventos e práticas de letramento acadêmico, como a produção de relatório, seminários. $\mathrm{Na}$ esfera profissional, o sujeito estagiário, interage com outros sujeitos, com os quais estabelece relação distinta da relação professor-aluno, e participa de eventos e práticas de letramento profissionais, tais como elaborar plano de aula, selecionar materiais, ministrar aula para uma turma de alunos da educação básica. Ao funcionar como interseção entre esses dois mundos, o estágio supervisionado pode contribuir para letramentos híbridos do estagiário e para a construção da sua identidade profissional docente, configurando-se como um entrelugar socioprofissional.

No entanto, para que o potencial reconfigurador de identidades do estágio como entrelugar socioprofissional possa prevalecer, entendo ser necessário que as práticas acadêmicas se articulem com as práticas exigidas no local de trabalho do professor.

$\mathrm{Na}$ análise de uma das disciplinas anuais de estágio em Língua Portuguesa ministrada por mim, encontrei dois tipos de práticas existentes: i) práticas mais claras, com objetivos compreensíveis e mais colaborativas e ii) práticas "de mistérios" (cf. LILLIS, 2001), mais obscuras e pouco compreensíveis. Na próxima seção, apresento um exemplo deste último tipo de prática existente no contexto estudado e, na sequência, uma prática colaborativa, que pode ser vista como alternativa aos "mistérios" do letramento acadêmico.

\section{Rescrita do plano de aula: uma prática de mistério}

Lillis (2001), uma das pesquisadoras representantes da vertente de estudos conhecida como "Letramentos Acadêmicos", intitula práticas institucionais de mistério aquelas práticas acadêmicas que, ancoradas numa concepção homogênea da comunidade acadêmica, toma como pressuposto uma série de convenções da escrita acadêmica, ligadas à ideologia dominante, que, desconhecidas pelos menos familiarizados com tais convenções, tornam-se obscuras e acabam limitando a participação deste público no Ensino Superior.

Uma das práticas que se constituiu como prática de mistério no contexto da disciplina de estágio diz respeito à reescrita do plano de aula. Como parte das atividades de estágio, os alunos estagiários deveriam ministrar duas aulas a cada ano do ensino fundamental II e a cada série do ensino médio, perfazendo um total de 14 horas de regência. Para tanto, eles teriam de elaborar planos de aula e enviar a mim, a professora orientadora, que faria a revisão dos planos com comentários para que os estagiários reescrevessem os planos, o enviassem novamente para orientação para ver se haveria mais modificações necessárias e, então, poder ministrar as regências. 
Ainda que a produção de plano de aula não se configure como um gênero acadêmico prototípico (como a resenha ou o artigo acadêmico), a prática da reescrita, fundamentada por um discurso teórico acadêmico que a concebe como parte do processo de escrita, não apresentava objetivos claros para alguns estagiários. A ausência de um sentido para a reescrita do plano de aula, uma solicitação da formadora acadêmica, a caracteriza como uma prática de mistério, como é possível perceber no seguinte trecho de diário de campo:

\section{Excerto 1: reescrita do plano de aula - o "vai e volta"}

Assim disse o aluno: "Como que eu devo fazer o plano de aula para não precisar ficar no vai-e volta?" Isso porque a aula era sobre análise linguística e foram apresentados exemplos sobre trabalho por essa perspectiva. [Nota de campo, 7/4/2012]

A fala do estagiário é acompanhada de um acento valorativo sobre a reescrita do plano de aula como um trabalho fastidioso, interminável, o que é construído principalmente pela expressão "vai-e-volta", que cria esse efeito de sentido, em vez de culminar em uma etapa significativa do processo de produção do plano de aula - objetivo esperado por mim, na posição de formadora.

Em entrevista com outro sujeito de pesquisa, realizada um semestre depois de concluída a graduação, também é indiciado o desencontro entre os propósitos de reescrita do plano de aula da professora formadora e os do outrora estagiário:

\section{Excerto 2: a falta de parâmetros na produção do plano de aula}

1 Orestes: (...) em relação ao relatório, o relatório ajuda, sim, eu acho que tem que ser bem

2 corrigido, que tem que voltar, quantas vezes for necessário e refazer, corrigir até... até o

3 professor achar que tá bom, porque a pró/ o próximo professor que vai avaliar esse relatório é

4 ele mesmo, e se ele não tiver um parâmetro daquilo que é bom é:: COmo ele vai avaliar? ((pausa

5 de quase 2 seg)) Peraí... se eu entregasse isso aqui pra professora... ela ia falar que tá bom? Não,

6 ela ia falar que tá um lixo... poxa, se ela que estuda faz... dez anos tá falando que tá um lixo

7 ((fala com riso sutil)) alguma coisa de ruim, alguma coisa de errado deve ta aqui, né? ((sério))

8 deixa eu olhar de novo, deixa eu verificar... se realmente tá bom ou que/ ou pelo MEnos o que

9 eu posso melhorar, ((fala mais devagar)) agora se você não tem parâmetro ((volta ao ritmo

10 anterior)) você não tem como comparar, então eu acho que, por exemplo, essas aulas deveriam

11 ser dadas, mas deveria ser batido mais nessa questão de parâmetro "olha, gente, esse é o

12 parâmetro de uma boa aula, se vocês quiserem dar uma boa aula, essa aula tem que ser

13 preparada a esse nível"... entendeu?

14 (...)

15 Orestes: não, não é isso é assim eu falo assim você/ você deixa claro pro aluno que o seguinte

16 por exemplo se a aula foi pra sua mão e voltou pra mão dele é porque não está bom... mas assim

17 com ((riso sutil na fala)) essas palavras sabe assim? "ó... não tá bom" ((pausa de quase 2 seg))

18 por quê? porque ISSO vai dar uma base para o aluno, mas por que que não tá bom? ((pausa de 2

19 seg))

20 Marília: uh-hum

21 Orestes: AÍ vai nascer uma outra discussão que é essa/ ess/ el/ ele vai começar a aprender a se

22 avaliar porque PEN-SA NIN-GUÉM ia mandar um negócio... pra uma professora de ((diz o

23 nome da instituição)) que não achasse que tivesse bom 
Neste momento da entrevista, em resposta à pergunta feita por mim, na posição de pesquisadora, sobre a função dos relatórios de estágio, Orestes ${ }^{5}$ responde tendo em vista desde o processo de elaboração dos planos de aula ${ }^{6}$ (uma vez que estes também compunham o relatório final). A apreciação valorativa de Orestes para a reescrita do plano de aula é a de que a prática resulta de falta de conhecimento suficiente. Tal apreciação indicia que a prática de reescrita se sustenta em um modelo de letramento acadêmico de mistério, baseado em uma dimensão escondida, conceito designado por Street (2010) para se referir aos critérios implícitos utilizados por membros acadêmicos dotados de poder para avaliar artigos científicos.

Para Orestes, o que leva à reescrita do plano é a falta de explicitação das convenções de escrita desse texto profissional e de seus critérios de avaliação ("se a aula foi pra sua mão e voltou pra mão dele é porque não está bom...", linha 16), o que o sujeito menciona como "falta de parâmetro" do que se espera dos estagiários para a produção desse texto profissional ("se você não tem parâmetro você não tem como comparar", "deveria ser batido mais nessa questão de parâmetro", linhas 9 e 11). O conflito é percebido por Orestes não como um aspecto cultural da instituição acadêmica, mas como uma questão particular da formadora acadêmica, conforme o modo como ele posiciona a pesquisador: no papel de professora. São marcas de posicionamento os usos do pronome "você" e do pronome possessivo "sua", em referência à pessoa com quem se fala, em "falo assim você/ você deixa claro pro aluno que o seguinte por exemplo se a aula foi pra sua mão e voltou pra mão dele" (linhas 15 e 16).

Contudo, ao trazer como sugestão a explicitação dos parâmetros de avaliação do plano pela classificação dos textos como "bons" ou "ruins" ("olha, gente, esse é o parâmetro de uma boa aula, se vocês quiserem dar uma boa aula, essa aula tem que ser preparada a esse nível", linhas 11 a 13, "com essas palavras sabe assim? ó... não tá bom", linha 17), Orestes reproduz uma voz acadêmica dominante, que legitima a prática do feedback. Nessa perspectiva, os textos dos alunos universitários, concebidos como um produto (e não um processo), seriam julgados por meio de comentários fechados do formador acadêmico, tendo em vista parâmetros pré-definidos, que bastam ser conhecidos para que todos os alcancem. Trata-se de um modelo que Lea e Street $(1998 ; 2006)$ designam como "modelo das habilidades cognitivas", em que a escrita se define como um conjunto de habilidades transferíveis de um contexto a outro. Os aspectos situados e identitários da escrita não são reconhecidos nessa abordagem.

Predomina, portanto, no discurso de Orestes, vozes tradicionais, hegemônicas, que circulam na academia e na escola, as quais estão alicerçadas no conceito autônomo de letramento (a escrita como uma habilidade cognitiva individual), e também numa concepção homogênea da comunidade acadêmica, que leva à visão de déficit em relação aos alunos, a de que estes precisam suprir as lacunas em sua produção escrita. Nota-se, assim, no discurso do ex estagiário, uma construção de identidade acadêmica, que reproduz o discurso acadêmico hegemônico. Para Orestes, a prática da (re)escrita do plano de aula não é significativa para o fortalecimento da identidade profissional docente e não colabora para a construção do estágio

\footnotetext{
${ }^{5}$ Foram usados pseudônimos para proteger a identidade dos participantes, conforme previsto no Termo de Consentimento Livre e Esclarecido (TCLE), devidamente preenchidos e assinados pelos sujeitos.

${ }^{6}$ Antes de dar essa resposta, ao ser indagado sobre a função do relatório de estágio, Orestes havia perguntado se era "todo o relatório ou só o final", em alusão à elaboração dos planos de aula, ao que eu respondi "todo o relatório", o que possibilitou ao sujeito tecer considerações específicas sobre o plano de aula.
} 
como um lugar de trânsito entre as esferas (re)configurador de identidades, isto é, um entrelugar socioprofissional.

Se, por um lado, a reescrita do plano de aula pode ser considerada como uma prática obscura, "de mistério", para alguns estagiários; por outro, a referida disciplina de estágio também proporcionou práticas mais explícitas, abertas à agência dos alunos, consoante apresento na seção a seguir.

\section{Partilha de trajetória leitora pelo blog: uma prática colaborativa}

Com a turma da disciplina de estágio supervisionado II, eu havia criado um blog, com o objetivo de incorporar o uso das novas tecnologias em sala de aula na formação docente e também de proporcionar um espaço que pudesse ampliar as discussões feitas em sala de aula, além de constituir também em um espaço para troca de materiais e de experiências entre os licenciandos. A proposta era a de que os alunos utilizassem livremente o blog, postando textos e materiais espontaneamente, e não só para realizar algumas atividades propostas por mim neste espaço. Poucos alunos fizeram postagens espontâneas no blog ${ }^{7}$, a maioria respondia às atividades solicitadas por mim, a formadora acadêmica.

Devido à baixa participação espontânea, posso dizer que o blog da disciplina não fortaleceu a escrita colaborativa, própria deste gênero virtual. Não obstante, posso afirmar que houve um movimento inicial de colaboração em uma atividade de produção da trajetória leitora, proposta por mim.

Baseada na pesquisa de Guedes-Pinto et al (2008) sobre narrativa de professoras alfabetizadoras, propus um exercício de revisitação da memória, com auxílio do que as autoras chamam de "muletas de memória". Levei para a sala de informática uma diversidade de livros, desde coleção de paradidáticos e livros infanto-juvenis até obras do cânone literário. Esparramei os livros em uma mesa que não tinha computador para que os alunos ficassem à vontade para se aproximar, olhar, folhear os livros, e solicitei que cada um escrevesse no blog a sua trajetória leitora. Eu já havia postado a minha própria trajetória leitora, não só para que compreendessem a proposta, mas para que eles também conhecessem a minha história e se sentissem mais à vontade para compartilharem suas histórias pessoais, seguros de que não haveria nenhum julgamento, visto que o objetivo era proporcionar uma troca significativa entre todos da turma. A aula terminou com a finalização da produção das narrativas pelos alunos. Antes da próxima aula, comentei todas as trajetórias postadas pelos alunos, que também haviam sido comentadas por outra aluna estagiária. No próximo encontro, fiz uma roda de discussão com os alunos para discutirmos sobre a experiência da produção das trajetórias de leitura e suas implicações para a formação docente. Nessa roda, algumas alunas estagiárias destacam que esta atividade havia sido muito significativa, em especial Lavínia que havia comentado todas as trajetórias de leitura dos colegas - conforme podemos perceber no dado de interação em sala de aula abaixo transcrito:

\footnotetext{
7 Algumas aulas eram agendadas por mim no laboratório de informática da universidade para que os alunos realizassem atividades no blog no horário da aula. Excetuando-se esta situação, somente dois alunos estagiários fizeram mais de cinco postagens espontâneas, compartilhando notícias relacionadas à educação, materiais e links para a turma, e cinco alunos estagiários fizeram até duas postagens espontaneamente. A turma era composta por aproximadamente trinta alunos.
} 


\section{Excerto 3: narrativa da trajetória de leitura pelos alunos estagiários}

1 Marília: (...) o objetivo pelo qual eu pedi pra vocês escreverem essa trajetória leitora é a gente 2 pensar nas implicações né? da... da minha constituição como lei/ como leitora para a formação 3 de leitores porque vocês estão num papel né? de professores em formação que vão formar 4 leitores né? (...) como foi né? essa experiÊNcia de elaborar essa trajetória, como foi essa prática, 5 esse exercício... se alguém achar realmente que não teve sentido, pode falar, foi um exercício 6 normal, como uma atividade que a gente faz aqui na universidade, ou não ou se teve al/ algum 7 significa::do ou então como é que foi recordar, ai foi gostoso fazer essa busca na na memó::ria 8 né? é:: ((ouve-se uma risada ao longe)) me reconhecer leitor, lembrar dos primeiros livrinhos, 9 então eu queria que vocês falassem nesse primeiro momento como que foi né? essa prática, esse 10 processo de revisitação aí na memória pra escrever essa trajetória

11 Perséfone: ah pra mim foi MUIto prazeroso

12

13

21 ((risos de Marília))

22 Marília: ((rindo e em voz alta)) eu percebi

23 Lavínia: adorei muito, muito, muito

24 ((risos)) ((conversas ao fundo))

25 Lavínia: eu achei assim pra mim foi muito interessante porque:: mesmo nas aulas que a gente 26 tá discutindo isso há muito tempo de... de como é importante pros alunos concurso, de ter uma 27 atividade prática assim mesmo que a a atividade prática seja um concurso, seja um curso de 28 redação... aí tudo bem pra mim assim não tudo bem a gente vai fazer, mas eu não tinha a 29 noÇẪO ainda de como isso era importante MESmo eu só fui p/ nossa como é legal isso porque 30 eu lembrei que pra MIM foi muito importante

31 Marília: uh-hum

32 Lavínia: e eu não tinha lembrado assim da MInha posiÇÃO, como como era importante pra 33 MIM isso e quando eu comecei a pensar eu falei assim "nossa, mas como eu me envolvi quando 34 teve concurso" e era terceiro colegial já assim pode/... assim às vezes (as pessoas) "ah mas com 35 os pequenininhos dá mais certo", não era o terceiro colegial, quando teve o concurso da Nestlé e 36 foi um envo/ um envolvimento toTAL assim eu achei MUIto muito interessante, eu gostei 37 muito de fazer... então pra mim ganhou mais senTIdo isso de levar isso também para os meus 38 alunos agora como... como:: como docente né? como formadora... porque pra mim era tudo 39 muito assim "ai tem que fazer? então a gente vai fazer, ai é legal fazer? é legal fazer, então a 40 gente faz", mas depois que eu pensei nisso nossa, realmente é importante pra mim foi muito 41 importante, então pra eles também vai ser... então eu gostei MUIto, muito, muito... e:: a 42 questão de em casa né? como... essa questão às vezes eu vi todo mundo falando, citando a 43 (família) ((sobreposição de vozes, outra pessoa parece dizer algo como os pais)) diferente da 44 (Perséfone) que veio do pai e a maioria foi da mãe, de ver a mãe lendo, eu vi minha mãe lendo 45 em casa e eu tinha muita vontade de ler junto ((vozes ao fundo)) porque o que que ela tá lendo?

46 (eu queria ler junto) (...)

Neste excerto, referente aos primeiros minutos da aula, a resposta positiva de duas alunas estagiárias à atividade de produção escrita da trajetória de leitura no blog da turma é evidenciada pelo uso de palavras do eixo semântico do prazer "prazeroso" (linha 11), "interessante" (linha 25), "gostoso" (linha 18), "adorar" (linha 23: "adorei muito, muito, muito") e "gostar" (linha 41: "eu gostei MUito, muito, muito..."), acompanhadas do intensificador "MUIto", que é utilizado reiteradas vezes e com ênfase vocal. 
O objetivo da atividade é explicitado por mim (linhas 1 a 4), a professora formadora, logo no início da discussão: refletir sobre o próprio processo de constituição leitora, enquanto professor em formação, a fim de, (re)conhecendo o seu processo e o do outro, refletir sobre o (futuro) processo de formação de leitores.

Ainda que seja feito um questionamento a respeito da produção da narrativa, o meu discurso enquanto formadora tende a caracterizar a atividade como positiva, significativa e, de certa forma, prazerosa, que agrade o gosto (seja "gostoso", linha 7), inclusive pela própria descaracterização da atividade como uma prática de letramento acadêmico, embora o seja. Tal posicionamento fica evidente, principalmente, pela relação de oposição marcada pelo operador "ou", que introduz elementos alternativos, de um lado, "o que a gente faz na universidade", de outro, o que tem algum significado: "pode falar foi um exercício normal, como a gente faz aqui na universidade, ou não ou se teve al/ algum significa::do" (linhas 5 a 7).

A resposta de Perséfone e Lavínia evidencia um alinhamento ao meu posicionamento de professora formadora, conforme a fala de Perséfone: "uma atividade mais voltada pro prazer acho que do que pra obrigação mesmo de cumprir alguma atividade alguma coisa nesse sentido" (linhas 16 e 18). O discurso das estagiárias evidencia ainda que a escrita das narrativas mobilizou as experiências vividas pelas alunas: "eu começo a lembrar de coisas que eu NÃO t/ não pensaria pra escrever, mas escrevendo a gente vai lembrando" (linhas 14 e 15). Considero a mobilização das experiências importante para a construção da identidade profissional, sendo determinante para a mudança identitária de Lavínia indiciada na sua mudança discursiva.

O dêitico "agora" (linha 38) sinaliza o momento em que, ocupando o lugar social demarcado em sua fala ("como docente", "como formadora"), Lavínia, se reposiciona e ressignifica a abordagem de partir da prática social, como um concurso, para trabalhar a leitura na sala de aula, que se torna significativa, "ganhou mais senTIdo" (linha 37); em contraposição a um momento anterior, marcado pelo pretérito - "era tudo muito assim" (linhas 38 e 39) -, de obediência ao discurso da formadora, sem análise de sua pertinência: "ai tem que fazer? então a gente vai fazer, ai é legal fazer? é legal fazer, então a gente faz" (linhas 39-40). É do lugar de professora em formação, após ter vivenciado o processo de rememoração da sua trajetória leitora na disciplina de estágio, que a estagiária Lavínia concebe o discurso teórico sobre a prática social como ponto de partida para o trabalho pedagógico com a leitura e escrita como, de fato, relevante e significativo para a formação do aluno da escola básica. O olhar para si de um lugar diferente daquele ocupado no passado, no decorrer de sua constituição leitora, suscitado pela construção discursiva de sua narrativa pessoal, propiciou-lhe um excedente de visão (BAKHTIN, 2003), no qual vendo-se "outro" pela distância espaço-temporal do presente - na relação com outros (pai, mãe, professor), a estagiária pôde ver a si mesma, a sua trajetória, e (re)conhecer a relevância de algumas práticas, valorizadas pelo discurso da formadora, na formação do aluno-leitor: "eu só fui p/ nossa como é legal isso porque eu lembrei que pra mim foi muito importante" (linhas 29 e $30)$.

A identificação e retomada do discurso teórico da formadora é feita com uso da expressão "a gente" (linha 25), que, diferentemente do uso analisado acima, inclui a professora formadora junto com os estagiários, sugerindo interação mais simétrica entre 
ambos no contexto das aulas de estágio: "mesmo nas aulas que a gente tá discutindo isso há muito tempo de de como é importante pros alunos concurso, de ter uma atividade prática assim mesmo que a a atividade prática seja um concurso" (linhas 25-27). A valoração do discurso da formadora passa a ser outra, extremamente positiva, depois que a estagiária realiza essa atividade discursiva de reconstrução de sua própria trajetória no blog. Além da contraposição do tempo presente, indicado pelos termos "então" (linhas 37 e 41) e "agora" (linha 38) e do pano de fundo anterior à mudança, com o pretérito imperfeito, "para mim era tudo muito assim" (linhas 38-39), o operador argumentativo contrajuntivo "mas" também indicia a mudança de posicionamento de Lavínia, inicialmente de atendimento ao discurso acadêmico da formadora, tomando-o como um discurso de autoridade, inquestionável ("ai tem que fazer? então a gente vai fazer, ai é legal fazer? é legal fazer, então a gente faz" - linhas 39-40), para a apropriação desse discurso ("ganhou mais senTIdo" - linha 37), reconfigurando-o como voz internamente persuasiva (BAKHTIN, 2003).

A análise desse excerto de interação em sala de aula mostra que houve um movimento colaborativo propiciado não pela tecnologia em si, mas por uma atividade significativa que parece favorecer (re)posicionamentos identitários dos estagiários na reconstrução de sua trajetória leitura. E o blog permitiu uma rede de interação mais dinâmica nesta atividade, pois possibilita que todos tenham acesso aos textos uns dos outros e podem, além da leitura, tecer comentários sobre estes textos, a exemplo do que fez Lavínia de livre iniciativa.

Pelos aspectos aqui apontados, considero que a partilha das narrativas sobre as trajetórias de leitura dos alunos constitui-se em uma prática colaborativa, aberta à voz do aluno e fortalecedora da sua agência, portanto, uma alternativa às práticas de mistério.

\section{Algumas (in)conclusões}

Assim como a finalização da pesquisa não encerra as possibilidades de reflexão sobre o tema, o fechamento deste artigo não finaliza a discussão; pelo contrário, abre caminhos para o fortalecimento de um importante debate na universidade, em especial na formação docente, que diz respeito à promoção de abordagens de ensino culturalmente sensíveis para a educação superior, semelhante ao que Erickson (1986) propõe que seja a compreensão das práticas escolares, isto é, levando em consideração a perspectiva dos sujeitos, sem julgamentos, para que se possa promover práticas significativas para estes. E não só na disciplina de estágio supervisionado, mas nas demais disciplinas acadêmicas também.

No caso da disciplina de estágio, se, por um lado, o lugar de interface entre a esfera acadêmica e a profissional tem potencial reconfigurador de identidades e de fortalecimento dos letramentos híbridos do professor em formação; por outro, para que esse entrelugar socioprofissional possa assim ser configurado, é necessário que haja negociação entre as práticas de letramento acadêmico e profissional. Faz parte desse processo de negociação a promoção de práticas acadêmicas mais explícitas, compreensíveis quanto aos objetivos e modos de realização e fomentadoras da agência dos alunos. Uma prática profissional como a elaboração e reescrita de plano de aula pode se tornar opaca, pouco significativa para os aprendizes da profissão quando a solicitação acadêmica se realiza sob pressupostos não compartilhados pelos sujeitos envolvidos, como a noção da reescrita como parte do processo de escrita de um texto, marcando o desencontro entre os propósitos de letramento do formador 
e dos alunos estagiários. A atividade torna-se uma prática obscura para os sujeitos que buscam formas de evitá-la por meio de pergunta direta ao formador ("o que fazer para não ficar no vai-e-volta") ou de sugestão de parâmetros de avaliação. A reprodução da voz acadêmica dominante no discurso do professor recém-formado que traz como sugestão a classificação dos planos de aula dos alunos estagiários indicia que práticas de letramento acadêmico baseadas numa abordagem da escrita como habilidade cognitiva e de uma visão deficitária do aluno ainda se fazem presentes no contexto da educação superior.

Uma alternativa aos mistérios acadêmicos pode ser encontrada em práticas mais colaborativas, abertas à agência dos alunos estagiários, como foi a partilha das trajetórias de leitura propiciada pelo blog. Atividades como esta possibilitam aos alunos tornarem-se agentes do seu processo de formação, e, pela alteridade, se reposicionarem em relação ao discurso acadêmico do formador, fortalecendo a construção da identidade profissional. O movimento colaborativo é potencializado por um espaço que permite uma rede de interação mais dinâmica, como o blog, e se concretiza pela agência dos sujeitos, como Lavínia, que se engaja na atividade, lendo e comentando todas as atividades dos colegas.

Em uma mesa-redonda realizada no VI CLAFPL ${ }^{8}$, Pietri (2016) afirma que o estágio supervisionado funciona com base em uma tensão entre a cultura acadêmica e a cultura escolar e que tal tensão "parece se produzir pelo fato de a relação com o espaço e o tempo do trabalho docente na formação inicial (e continuada) se fazerem como um processo de estranhamento, de alteridade" (PIETRI, 2016, p.10). Referindo-se à falta de identificação do estagiário com a formação e com o contexto escolar, o autor defende que o estranhamento, ou a consideração da alteridade, resultante desta tensão não seja um problema, mas que "sejam as forças mobilizadoras para a produção discursiva dos professores em formação, em seu processo de elaboração de representações do trabalho docente" (PIETRI, 2016, p.10).

Para que este processo de estranhamento, de alteridade, possa ser encarado de modo positivo para a formação docente, como defende o autor, e trazer resultados profícuos para essa formação profissional, entendo ser necessário refletir sobre a "cultura acadêmica", ou sobre as práticas acadêmicas, visando à possibilidade de reposicionamentos discursivos e identitários em direção ao fortalecimento profissional, o que demanda práticas alternativas às práticas de mistério no contexto da educação superior.

\section{Referências}

BAKHTIN, M. [1979] Estética da Criação verbal. Tradução Paulo Bezerra 4a. ed. Martins Fontes, 2003.

BARTON, D.; HAMILTON, M. Literacy practices. In: BARTON, D; HAMILTON, M.; IVANIC, R. Situated Literacies: reading and writing in context. London and New York: Routledge, 2000.

\footnotetext{
${ }^{8}$ Intitulada "Práticas de estágio e aprendizagem de línguas". O trabalho de Pietri tem como título "O estágio supervisionado em ensino de línguas: a formação do professor entre a escola e a academia" e seu resumo encontra-se no Caderno de Resumos do VI CLAFPL, disponível em:

http://www.viclafpl.com.br/pt/programacao/caderno-de-resumos/. Acesso em 7 de dezembro de 2016.
} 
DE GRANDE, P. B. Formação continuada no local de trabalho do professor: possibilidades de agência e construção de sentidos para a docência. 2015. 263 p. Tese (Doutorado em Linguística Aplicada, Instituto de Estudos da Linguagem) - Universidade Estadual de Campinas (UNICAMP), Campinas, 2015.

ERICKSON, F. D. Qualitative methods in research on teaching. In: M. C. Wittrock (Ed.), Handbook of research on teaching. 3 ed. New York, NY: MacMillan, 1986, p. 119-161.

GUEDES-PINTO, A. L.; GOMES, G. G.; SILVA, L. C. B. Memórias de leitura e formação de professores. Campinas: Mercado de Letras, 2008.

HEATH, S. B. What no bedtime story means: narrative skills at home and school. Language in Society, v.11, n.1, p.49-76, april 1982.

KLEIMAN, A. Modelos de letramento e as práticas de alfabetização na escola. In: (Org.) Os significados do Letramento: uma nova perspectiva sobre a prática social da escrita. Campinas: Mercado de Letras, p. 15-61, 1995.

KLEIMAN, A. B.; SILVA, S. B. B. Letramento no local de trabalho: o professor e seus conhecimentos. OLIVEIRA, M. S.; KLEIMAN, A. B. (Org.). Letramentos múltiplos: agentes, práticas, representações. Natal: EDUFRN, 2008, p.17-40.

LEA, M.R.; STREET, B. Student writing in higher education: an academic literacies approach. Studies in Higher Education, Jun 98, Vol. 23, Issue 2, 1998, p. 157-171.

. The "Academic Literacies" Model: Theory and Applications. Theory Into Practice, 45(4), 2006, p. 368-377.

LILLIS, T. M. Student Writing: access, regulation, desire. Londres: Routledge, 2001.

MOITA LOPES, L. P. Afinal o que é lingüística aplicada? In: Oficina de lingüística aplicada. Campinas - SP: Mercado de Letras, 1996, p. 17-25.

PIETRI, E. O estágio supervisionado em ensino de línguas: a formação do professor entre a escola e a academia. Mesa-redonda "Práticas de estágio e aprendizagem de línguas". In: VI CLAFPL (Congresso Latino-Americano de Formação de Professores de Línguas), Londrina, 2016.

PIMENTA, S. G.; LIMA, M. S. L. Estágio e docência. 6. ed. São Paulo: Cortez, 2011.

REICHMANN, C. L. Tecendo o gênero profissional: o estágio como prática de letramento docente e formação identitária. In: REICHMANN, C. L.; MEDRADO, B. P. (Org.). Projetos e práticas na formação de professores de língua inglesa. João Pessoa: Editora da UFPB, 2012, p.101-124.

Letras e letramentos: escrita situada, identidade e trabalho docente no estágio supervisionado. Campinas: Mercado de Letras, 2015.

ROJO, R. H. R. Gêneros discursivos do Círculo de Bakhtin e multiletramentos. In: (org.). Escol@Conect@d@: os multiletramentos e as TICs: São Paulo: Parábola, 2013, p. 13-36. 
SCRIBNER, S; COLE, M. The psychology of literacy. Cambridge, Mass., Harvard University Press, 1981.

STREET, B. Literacy in theory and practice. Londres: Cambridge University Press, 1984. - Dimensões "escondidas" na escrita de artigos acadêmicos. Perspectiva. Florianópolis, v.28, n. 2, 541-567, jul./dez. 2010.

Eventos de letramento e práticas de letramento: teoria e prática nos Novos Estudos do Letramento. In: MAGALHÃES, I. (Org.). Discursos e práticas de letramento: pesquisa etnográfica e formação de professores. Campinas: Mercado de Letras, 2012, p. 69-89.

VALSECHI, 2016. Afinal, o que é o estágio supervisionado? De labirinto a entrelugar: o estágio proposto pela universidade na visão dos estagiários. 2016. 298 p. Tese (Doutorado em Linguística Aplicada, Instituto de Estudos da Linguagem) - Universidade Estadual de Campinas (UNICAMP), Campinas, 2016.

VOLOCHINOV, V. [1929] Marxismo e filosofia da linguagem.11.ed. Tradução Michel Lahud e Yara Frateschi Vieira. São Paulo: Hucitec, 2004. 